\title{
UN PALACIO EN FIESTA: TROYANO ACQUAVIVA Y LA CELEBRACIÓN POR LOS ESPONSALES DE CARLOS DE BORBÓN Y MARÍA AMALIA DE SAJONIA EN EL PALACIO DE ESPAÑA EN ROMA
}

\author{
Pilar Diez del Corral Corredoira \\ Universidade Nova de Lisboa
}

Fecha de recepción: enero 2015

Fecha de aceptación: mayo 2015

La embajada del cardenal Troyano Acquaviva (1735-1747) en Roma es todavía hoy un tema que merece una mayor atención a la vista de su importancia en la historia de las relaciones internacionales entre España y Roma en el Settecento. Troyano es un personaje de enorme interés no sólo para la historia de la diplomacia sino también para el arte. Hijo de los duques de Atri, comenzó muy temprano su carrera eclesiástica como comisionado del Clemente XI en 1712 y fue ordenado sacerdote en 1729, año en que también obtuvo el título de obispo. Su tío, el cardenal Francesco Acquaviva, embajador del monarca español desde 1716, lo tuvo bajo su protección y en ese mismo año fue nombrado camarero secreto de Clemente XI. En 1725 regresa a Roma desde Ancona, donde estaba encargado del gobierno por orden de Inocencio XIII. Benedicto XIII lo nombró arzobispo de Filippopolis (actual Plovdiv) y su maestro de cámara, ascendiendo poco después a mayordomo del palacio apostólico.

\footnotetext{
1. Storace, Baldassare: Historia della familia Acquaviva Reale d'Aragona, Roma, 1738, esp. pp. 86-119; NicolinI, Fausto: «Troiano Acquaviva», en DBI, Instituto della Enciclopedia Italiana, Roma, 1960, vol. 1, pp. 198-99; OzAnam, Didier: Les diplomats espagnoles au XVIII siècle, Madrid-Burdeos, 1998, pp. 144145; Muniaín EDERRA, Sara: «Arquitecura efímera y diplomacia: Los Acquaviva y la imagen celebrativa de la monarquía española ante la Santa Sede (1721-1746)», Reales Sitios, 166 (2005), pp. 62-77; BARrIo Gozalo, Maximiliano: «La Embajada del cardenal Troiano Acquaviva d'Aragona ante la corte romana (1735-1747)», Cuadernos dieciochistas, 14 (2013), pp. 233-260.
} 
Su papel en la política exterior española comienza a ser de gran trascendencia cuando ejerciendo como representante oficioso de Don Carlos de Borbón, consigue el permiso del pontífice para que las tropas españolas, que habrían de hacerse con Nápoles, pudiesen atravesar la Península ${ }^{2}$. Durante su período como embajador español demostró ser una persona de carácter fuerte, no exento de enemigos ${ }^{3}$, amante del arte y de la música, y que supo continuar la política cultural de su tío ${ }^{4}$. Estaba llamado a ser una figura fulgurante puesto que su conocimiento del ambiente y el ceremonial romano, así como de las grandes familias con las que incluso tenía lazos familiares, lo convertían en un embajador único e idóneo para devolver a la monarquía española al espacio de poder que detentó con los Austrias y que después de la Guerra había sido gravemente dañado. Su embajada comenzó con grandes victorias políticas, pues el mismo año de su nombramiento, 1735, obtuvo de Clemente XII el arzobispado de Toledo y el capelo cardenalicio para el infante Don Luis, el menor de los hijos de Felipe V, de tan sólo siete años ${ }^{5}$. Su embajada comenzó entonces con gran brillantez, pero pasó también por momentos de gran tensión en la política exterior de España, que había quedado muy dañada después del desastroso resultado del tratado de Utrecht.

La escasez de fuentes primarias que nos hablan sobre sus gustos artísticos o sobre los gastos suntuarios que llevó a cabo en el palacio de España suponen un importante revés a la hora de poder reconstruir su embajada ${ }^{6}$. Una parte importante de la documentación relativa a sus primeros años como embajador se perdió irremediablemente en el

2. Los intereses del futuro rey de Nápoles son defendidos por Acquaviva en primer lugar de una forma no oficial, pero desde 1737 su papel se hará público e incluso contará con el apoyo del arzobispo Celestino Galiani (1681-1753), capellán mayor del Reino de Nápoles y enviado allí a Roma por el rey. Su misión consistía en apoyar a Troyano Acquaviva en las negociaciones entre la Santa Sede y Nápoles sobre las controversias jurisdiccionales y finalmente el concordato, que se firmaría el 2 de junio de 1741. Tanucci, Bernardo: Epistole, en Coppini, R. P., L. del Bianco y R. Nieri (ed.), Roma, 1980, p. 28, n. 2 y 3.

3. Resulta especialmente reveladora la mala relación con otros representantes del Reino de España como el cónsul en Florencia Salvador Ascanio o José García del Pino. Éste fue temporalmente archivero del Palacio de España y también notario del Rey en Roma, su nefasta relación con Acquaviva queda perfectamente retratada en las cartas que dirigió al marqués de Salas, que se conservan en el Archivo de Estado de Nápoles (388 Affari Esteri, Roma 1734-44, Leg. 1133).

4. En el mismo año de su muerte Gianbattista Vico (1668-1744) le dedicó su versión definitiva de los Principii di Scienza Nuova, publicado en Nápoles en 1744. Así mismo en su estrecha relación con Benedicto XIV hizo de intermediario entre el Papa y Voltaire en la famosa correspondencia que mantuvieron en los años cuarenta. Sobre su papel como comitente véase: ANTINORI, Aloisio: «Note su Troiano Acquaviva d'Aragona protoilluminista e comitente de Ferdinando Fuga», en Gambardella, Alfonso (ed.), Ferdinando Fuga 1699-1999. Roma, Napoli, Palermo. Studi sul Settecento napoletano, Nápoles, 2001, II, pp. 115-127 y AscenZI, Vanessa, «Trojano Acquaviva d'Aragona: un cardinale collezionista d'arte a Roma», Studi di storia dell'arte, 13 (2002), pp. 265-269.

5. Sobre este tema véase Barrio Gozalo, Maximiliano: El Real patronato y los obispos españoles del Antiguo Régimen, Madrid, 2004, pp. 109-110 y p. 195 (arzobispado de Toledo y de Sevilla respectivamente).

6. Para tener una visión general de los fondos documentales de la Embajada ante la Santa Sede véase: Pou i Martí, José María: Archivo de la Embajada de España cerca de la Santa Sede: índice analítico de los códices conservados en la Biblioteca, Roma, 1925. 
incendio que asoló el archivo de la Embajada en enero de 1738 y a ello hemos de añadir que no se conserva prácticamente ningún libro de pagos. En el archivo de Estado de Nápoles se pueden consultar cartas pertenecientes a «Casa Real», que sobrevivieron parcialmente a un bombardeo en la Segunda Guerra Mundial, en las que se puede reconstruir una parte de las actividades del embajador y que en cierta medida arrojan algo de luz sobre su persona. En los fondos del antiguo archivo de Asuntos Exteriores, actualmente en el Archivo Histórico Nacional, se conservan sus oficios de embajada, reales órdenes, correspondencia extraoficial y entre otras cosas, algo de documentación dispersa como un diario parcial de Anielo Nipho, su archivero en Roma. Éste último nos da cuenta de una manera bastante completa del día a día de la embajada, pero en general no desarrolla los aspectos de tipo artístico que nos podrían interesar. La falta de los libros de pagos de la embajada suponen una enorme pérdida, puesto que en los que conservamos de Bentivoglio, por ejemplo, podemos rastrear la compra de obras de arte o los encargos particulares del embajador y cotejarlos con el diario, permitiendo así reconstruir quiénes fueron los artífices de la maquinaria efímera o de las composiciones musicales, que normalmente no aparecen citados en las «relaziones», así como los artistas que normalmente trabajaron para el embajador.

La celebración en el palacio de España los días 6 y 7 de septiembre de 1738 por el matrimonio de Don Carlos de Borbón y Doña María Amalia de Sajonia, Reyes de Nápoles y las Dos Sicilias, es el punto más brillante de representación pública de esos primeros años de la embajada de Troyano. Sin embargo, para entender su importancia, es necesario retrotraernos a la famosa ruptura de las relaciones diplomáticas en 1736 entre Felipe V y el papa Clemente XII, que marcó profundamente el inicio de su embajada.

Los conflictos diplomáticos entre el pontífice y la embajada española eran un aspecto bastante común desde la Guerra de Sucesión 7 . Esas tensiones habían alcanzado el clímax en la ruptura de relaciones de 1718 , resultado de una situación muy compleja que se puede resumir en dos incidentes que hicieron saltar por los aires el precario equilibrio post-Utrecht. Por un lado, el pontífice había descubierto la existencia de un arsenal oculto en la Villa Medici, que estaría a disposición de la embajada española en caso de que fuese atacada y por otro lado, las constantes levas forzosas llevadas a cabo en el ámbito del Foro Hispanicum, esto es, la zona de influencia del palacio de España, que disfrutaba del estatuto especial libre de las injerencias pontificias ${ }^{8}$. La libertad con la que actuaban allí las tropas españolas era total, lo que condujo a no pocos abusos, denunciados inclusive por los propios embajadores, que veían minada su capacidad

7. Martín Marcos, David: El papado y la Guerra de Sucesión Española, Madrid, 2011 y OCHOA BrUN, Miguel Ángel: Embajadas Rivales: La presencia diplomática de España en Italia durente la Guerra de Sucesión, Madrid, 2002.

8. Anselmi, Alessandra: «Il quartiere dell'Ambasciata di Spagna a Roma», en CAlabi, Daniela y LANARo, Paola: La città italiana e i luoghi degli stranieri (ss. XIV-XVIII), Bari, 1998, pp. 206-221. Sobre la cuestión del Foro Hispanicum veáse García SÁncheZ, Jorge: «Un privilegio diplomático conflictivo en la Roma del siglo XVIII: La jurisdicción de la Corona española en el distrito del Foro Hispanicum», Espacio, Tiempo y Forma. Serie IV. Historia Moderna, t. 18-19 (2005-06), pp.203-222. 
de control. Lejos de quedar zanjado el asunto, los continuos incidentes llevaron a un notable crecimiento del sentimiento antiespañol en Roma. Al mismo tiempo, las relaciones de la corona española con el Pontífice no se encontraban en un momento muy bueno puesto que el Papa no había concedido la investidura del joven rey de Nápoles, asunto que permanecía en la agenda del cardenal Acquaviva desde el mismo día de su nombramiento como embajador ${ }^{9}$. A todo ello hemos de añadir que la ofensiva del duque de Montemar en la Toscana contra la tropas imperiales hizo más necesario que nunca el reclutamiento de nuevos soldados y ello llevó a numerosos atropellos de las tropas en Roma.

En este contexto extremadamente delicado, en marzo de 1736, un grupo de trasteverinos enfervorecidos, después de apedrear a soldados españoles y las armas del infante español en el palacio Farnese, decidió atacar el palacio de España. La respuesta fue contundente y más de ciento cincuenta soldados y civiles se atrincheraron en la plaza delante del palacio para plantarles cara ${ }^{10}$. Los incidentes fueron de tal naturaleza que Felipe V mandó orden de que todos sus nacionales abandonasen Roma y rompió toda relación con los Estados Pontificios. Los españoles tenían la obligación so pena de multas de dejar la ciudad e instalarse temporalmente en Nápoles ${ }^{11}$.

La mudanza de toda la legación española no fue sencilla y conservamos un interesante testimonio de un artista español que partió en los primeros barcos hacia la ciudad partenopea y que describe con mucho detalle lo precipitado de esa marcha ${ }^{12}$. Por su parte la respuesta del Papa vino a través de la Congregación de Cardenales que, el 11 de mayo de 1736, pergeñó un decreto en el que se suspendería de sus cargos a aquellos religiosos que abandonasen la ciudad sin su permiso. Aunque no se mencionaba explícitamente a los españoles, era obvia la intención del mencionado decreto, sin embargo ello no impidió el éxodo ${ }^{13}$.

9. El vínculo con el joven rey es ya antiguo, puesto que fue a él al que se dirigió al poco de la muerte del cardenal Bentivoglio (30.12.1732) para solicitar su apoyo para el puesto de embajador ante la Santa Sede (ASN, Affari Esteri, Fasc. 831, disp. 428, Parma, 5 de enero d 1733) Citado de Ascione, Imma: Carlo di Borbone, Lettere ai sovrani di Spagna. Vol I: 1720-1734, Roma, 2001, p. 262, n. 341. El asunto de la investidura era un arma habitual del papado para negociar con los reyes españoles, por lo que no resulta sorprendente que Troyano se encuentre con este problema. Sobre este tema véase: MARTín Marcos, David: «El proyecto de mediación de la Santa Sede como alternativa a la Guerra de Sucesión Española», Revista de Historia Moderna. Anales de Alicante, 25 (2007), pp. 129-147, esp. 140-144.

10. Un relato sobre lo sucedido muy rico en detalles se puede hallar en VALESIO, Francesco: Diario di Roma, vol. V, Milán, 1979, pp.849-854.

11. De hecho incluso napolitanos y sicilianos si querían permanecer en la ciudad tenían que justificar debidamente las razones. ASN, 492. Aff. Esteri Roma, leg. 1239 (Carta di Giovanni Porta al suo padrone. 24 maggio 1736).

12. El passeo por Roma concluido en Nápoles (1736), anónimo, Archivo de la Ópera Pía de Montserrat. Este documento fue publicado íntegro por Pérez Estévez, Rosa María y GonzÁlez Martínez, Rosa María: Pretendientes y pícaros españoles en Roma. Siglo XVIII, Valladolid, 1992.

13. GARCÍA SÁNCHEZ, Jorge, «Un privilegio diplomático», 2005, p. 209. 
El restablecimiento de la relaciones fue un proceso muy lento y que obligó al cardenal Troyano Acquaviva a demostrar su dominio del medio diplomático en un entorno un tanto hostil. Gracias al diario de Nipho sabemos que el cardenal regresó a Roma de incógnito el 9 de marzo de 1737 y que todavía a 14 de abril no se habían levantado las armas en la fachada del palacio ${ }^{14}$. Durante varios meses, el embajador continuó residiendo en Roma de incógnito y, por tanto, sujeto a unas determinadas normas de etiqueta que lo diferenciaban de los demás embajadores. Es más; su papel público era exclusivamente el de cardenal, no de representante de España, todo ello a la espera de una compensación por parte del Papa ${ }^{15}$. En estos términos se entiende su participación en la fiesta de la Santísima Trinidad el 16 de junio. Se celebraba la canonización de los cuatro beatos, Padre Vicente de Paula, Juan Francisco de Regis, Juliana de Falconieri y Catherina Piisca Adurna en San Juan de Letrán: «asistiendo Su Santidad solamente en el tiempo que devía pronunciar el decreto de Santificazion. Su Eminencia en execución de las órdenes de Su Magestad de hazer todos los actos correspondientes a la dignidad de cardenal solamente, y no a las del carácter de ministro, intervino en dicha función, y mandó poner luminarias en este Real palacio de una hilera de achas en los balcones y otra de padela en la plaza» ${ }^{16}$.

El 26 de septiembre de 1737 se firma el concordato entre Felipe V y el Pontífice, que pone fin a este año largo de tensiones. Sin embargo, a pesar de ello o quizás por causa del tardío concordato, Troyano decide abandonar la ciudad para pasar la villeggiatura en Caprarola, en donde desde la primavera se estaban llevando a cabo reformas para acondicionar el palacio ${ }^{17}$. Según la correspondencia del notario Giovanni Porta, agente de la corte de Nápoles en Roma, sabemos que Troyano había encargado a Ferdinando Fuga las obras de acondicionamiento del palacio. Porta nos dice en una carta fechada en el 3 de mayo de 1737: «Il Cavalliere Fuga architetto della Real Casa mette adesso in pulito tutte le sue osservazioni, e sopra le medesime allorché mi saranno dà lui consegnate, io regolerò l'esposizione che l'Eccellenza Vostra potrà inviare alla maestà del Rè Nostro Sig. per adesso dirò solamente, che quella sontuosa singolarissima fabbrica va prendendo su altro aspetto, a attesa la generosa magnifica risoluzione della Maestà sua di preservarla da quelle rovine che sarebbero state inevitabili, se si fosse continuata ad ommettere i necessari rifarcimenti e ripari. Gli abitanti di Caprarola giubilano per questa reale determinazione, e in questo loro giubilo traspira lo costante attacamento, che nutriscono verso i suoi Serenissimi loro padroni» ${ }^{18}$.

14. Archivo Histórico Nacional (Madrid), Exteriores, SS 477, fol. 15.

15. Sobre la «vida de incógnito» en Roma véase José María DomíngueZ: Roma-Nápoles-Madrid: Mecenazgo musical del IX Duque de Medinaceli 1687-1710, Kassel, 2013, pp. 61-62.

16. AHN, Exteriores, SS 477, fol. 17.

17. El palacio de Caprarola era el lugar favorito del embajador para pasar sus vacaciones y formaba parte de los feudos heredados por Isabel de Farnesio a la muerte en 1731 de Antonio Farnese, el último duque de Parma.

18. ASN, Affari Esteri, Leg. 1240, vol. 493. 
El embajador parte para Caprarola el día 7 de octubre en compañía de la princesa di Santo Buono, su cuñado monseñor Caracciolo, don Pascual Acquaviva, el duque de Palombara y otros confidentes, y permanecen un mes escaso ${ }^{19}$. El 4 de noviembre Troyano ya estaba de regreso en su palacio y dio la orden de que se colocasen las armas del rey de España en la puerta principal y «lo mismo se ejecutó en el Palacio del Señor Cardenal Belluga, del Agente del Rey y del Correo de España, y del Marqués de

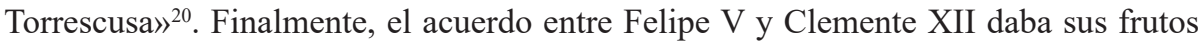
y al día siguiente el embajador sería recibido en audiencia ${ }^{21}$. Con este concordato se concluía un período de enormes tensiones entre el monarca español y el pontífice y permitía que Troyano Acquaviva pudiese ejercer de embajador del rey español con todo lo que ello conllevaba.

El año de 1738 se inicia con el incendio que destruyó una parte importante del archivo del palacio de España. En su correspondencia Troyano parece restar importancia al asunto, probablemente por estar ya preocupado por otras cuestiones, como la investidura que no llegaba, que junto a este nefasto incidente comenzaban a ensombrecer su fulgurante carrera como embajador. En palabras del notario García del Pino, que ejercía de amanuense improvisado copiando los documentos salvados del desastre: «Con motivo que de orden del Señor Cardenal Ministro me hallo resolviendo de las cenizas, que han quedado del deplorable incendio del Archivo del Rey Católico por no haber persona que se alentase a ejecutarlo, y que yo también en tan lastimoso estado seria inútil, si además de la practica del el, no me hallase con un índice de las Bulas y Breves, que años hà formé, que habiendo encontrado en el, aunque muy perdida del fuego, que en tan mal estado, que si no se preocupa su pronto registro, se perderá totalmente la memoria(...)»»22. Nos consta que la relación entre ambos todavía no estaba muy enrarecida, pero empeorará con el tiempo puesto que García del Pino reclamará que se paguen sus servicios y además denuncia con escasa delicadeza el poco interés del embajador en ese asunto. Lo cierto es que el incendio llega en un momento en que Troyano se encontraba inmerso en otros temas de mayor trascendencia para él y para la Corona, lo que explica su falta de implicación ${ }^{23}$.

19. ASN, Affari Esteri, Leg. 1240, vol. 493. Carta de 8 de octubre del 1737 de Giovanni Porta.

20. AHN, Exteriores, SS 477, fol. 18.

21. «El día 5 por la mañana fue su Eminencia con numerosos cortejos de Prelados y Caballeros y Vasallos y Feudatarios de su Majestad y del Rey de las Dos Sicilias a la audiencia de su Santidad, y de los Cardenales Corsini y Firrau para participarles como lo ejecutó la notica tan placible para Roma de haber el rey Nuestro Señor aprobado el tratado de ajuste concluido y firmado entre esta Corte y la de Madrid», AHN, Exteriores, SS 477, fol. 18.

22. ASN, Affari Esteri, Leg. 1240, vol. 493. Carta de García del Pino al marqués de Salas, fechada el 17 de marzo de 1739.

23. En sucesivas cartas García del Pino se lamenta amargamente de la mala relación que tiene con el cardenal Acquaviva y de los desprecios que le hace, así como de la pérdida de la documentación muy valiosa en el incendio y de cómo ha estado trabajando ocho meses sin recibir estipendio alguno. Además se niega a entregar las copias que posee de la documentación perdida por el precio que le ofrecen por considerarlo completamente insuficiente. La relación entre ambos empeora notablemente cuando el cardenal 
Esos temas que ocupaban la mente del cardenal son probablemente resultado de su prolongada estancia en Nápoles y de su situación ambivalente como representante de las dos coronas hispanas, la de España y la del reino de Nápoles y las Dos Sicilias. Su vínculo con Don Carlos se había estrechado a lo largo de los numerosos meses que pasó en la ciudad partenopea antes de regresar de incógnito a Roma en la primavera de 1737. El rey lo había nombrado «Procurador mandatario y Plenipotenciario (...) ante el enunciado y Santísimo Padre Clemente XIII» ${ }^{24}$ para que negociase la investidura de Don Carlos, que estaba demorándose mucho y por la que probablemente sufría grandes presiones de la reina Isabel de Farnesio, la principal impulsora de la causa de su hijo ${ }^{25}$. A ello hay que añadir que la firma del concordato entre Nápoles y Clemente XII también estaba sufriendo importantes retrasos (se concretará tan sólo en el 1741), por lo que el incendio del archivo del palacio de España era sin duda un problema que venía a acrecentar sus otras preocupaciones pero que carecía de la misma relevancia.

Conviene además recordar que en las mismas fechas el cardenal Acquaviva formaba parte activa de las intrigas de la corte napolitana cuyo objetivo último era acabar con el monopolio que ejercía el Conde de Santisteban, Manuel de Benavides y Aragón (1683-1748), sobre la figura del rey y el círculo cortesano creado ad hoc. Junto a Troyano estaban también el duque de Berwick (recientemente nombrado embajador en España), el conde de Fuenclara (embajador en Viena y que había llegado de Dresde con la joven María Amalia de Sajonia) y el hermano de Acquaviva, el duque de Atri, embajador extraordinario de los monarcas españoles. Todos ellos apoyaron a la nobleza local y a los oficiales en mando en la corte hasta que consiguieron destituir al todopoderoso Mayordomo del rey, que fue sustituido por José Joaquín de Montealegre entre $1738-1746^{26}$.

La ansiada investidura de don Carlos de Borbón como rey de Nápoles y las Dos Sicilias llegó el 12 de mayo del 1738, celebrada con mucha pompa en el palacio del Quirinal. La ceremonia contó con la presencia de la mayoría de los cardenales

Acquaviva escoge a un secretario italiano, Bernardo Tucci, para sustituir al recién fallecido Aniello Nipho en su puesto de archivero del palacio de España, vacante a la que obviamente aspiraba García del Pino.

24. AHN, SS 380, Correspondencia Extraordinaria, fol. 137.

25. Es importante resaltar que el duque de Atri, Domenico Acquaviva d'Aragona (1689-1745) hermano del cardenal Acquaviva, llevaba una correspondencia secreta con al reina española para mantenerla informada de los diferentes movimientos de la corte partenopea en aquel complicado año de 1738 (AHN, Estado, leg. 4823"; de VÁZQuez GeSTAL, Pablo: «'The system of this court’: Elisabeth Farnese, the Count of Santisteban and the Monarchy of the Two Sicilies, 1734-1738», The Court Historian, 14,1 (2009), pp. 23-47, p. 23 n.2).

26. VÁzQUEz GeSTAL, «The system of this court», 2009, p. 47. La habilidad política de Acquaviva se confirma a lo largo de su carrera, puesto que años después en el 1746 logra eliminar a su antaño aliado Montealegre y sustituirlo por su protegido Giovanni Fogliani d'Aragona (1697-1780). NiCOLINI, «Troiano Acquaviva», 1960, pp. 198-199. 
y fue un momento de enorme trascendencia en la carrera del cardenal Acquaviva ${ }^{27}$. Inmediatamente el Sacro Colegio lo sanciona como protector de Sicilia y como representante de Nápoles ante la Santa Sede. Tan sólo un mes después el embajador tendría ocasión de emplear su poder a la hora de la organización de la ceremonia de la Hacanea (Chinea), la primera bajo el nuevo monarca español ${ }^{28}$. El escaso tiempo que medió entre la investidura y la festividad incidió negativamente en la gestión de una fiesta de enorme trascendencia ${ }^{29}$. Tradicionalmente era el condestable Fabrizio Colonna el encargado de presidirla, que debía ser nombrado, pero que debió de ejercer de manera oficiosa como anfitrión. Acquaviva no desperdició la ocasión de interferir en la organización, puesto que impuso que se desarrollase ante el palacio Farnese, en vez de en la plaza Sancti Apostoli, en donde tradicionalmente se venía celebrando, dado que el palacio Colonna estaba sito allíi ${ }^{30}$. El traslado al palacio Farnese implicó una serie de inconvenientes logísticos que el condestable no dejó de manifestar, pero tenía una intencionalidad clara de poner de manifiesto la importancia de la dinastía Farnese, que ahora era española, y cuyas propiedades eran herencia del joven rey Carlos VII. Esta jugada maestra del cardenal Acquaviva sirve para entender el peso de la apropiación del pasado de una casa nobiliaria, así como la apropiación del espacio de la ciudad como escenario del poder, que constituía un acto de importancia nada desdeñable después de las recientes revueltas antiespañolas. En este caso, Acquaviva no podía ejercer de titular de esa celebración, que por tradición correspondía a los Colonna, pero su asociación al monarca de Nápoles y las Dos Sicilias era patente y tendría ocasión de demostrar su poder meses después en su propio palacio.

A lo largo del verano de 1738 se sucedieron las diversas celebraciones por el matrimonio de Carlos VII con María Amalia de Sajonia. Los esposos hicieron su entra-

27. Becattini, Francesco: Vida de Carlos III de Borbón: rey católico de España y de las Indias, 1790, vol.1, pp. 200-202. Sobre la ceremonia del posesso véase Sabina DE CAVI: «El posesso de los virreyes españoles en Nápoles», en Bernardo, García García y Krista de Jonge (coord.), El legado de Borgoña: fiesta y ceremonia cortesana en la Europa de los Austrias, Madrid, 2010, pp. 323-335.

28. La Chinea o Hacanea es una ceremonia en la que el reino de Nápoles hace acto de vasallaje ante el pontífice, que es el encargado de investir al nuevo monarca. La ceremonia consiste en la entrega de siete mil ducados de oro en un cáliz de plata acompañada por una numerosa comitiva de caballeros y nobles, encabezados por un caballo blanco. Este acto de homenaje de carácter jurídico e institucional se celebra la víspera de los patronos de Roma, San Pedro y San Pablo, y es una de la grandes celebraciones del calendario romano. Tiene un valor ritual enorme y además nos permite entender el equilibrio de poderes entre las familias romanas y napolitanas y su relación con la Santa Sede. Moore, John E.: «Building set pieces in Eighteenth-Century Rome: The case of the Chinea», Memoires of the American Academy in Rome, 43/44 (1998/1999), pp. 183-292 y Boiteux, Martine: «L'Hommage de la Chinea: Madrid-NaplesRoma», en Carlos José Hernando (coord.), Roma y España: un crisol de la cultura europea en la Edad Moderna, II, Madrid, 2008, pp. 831-846.

29. Un decreto del 12 de mayo de 1691 obligaba a los Grandes de España a asistir a la cabalgata de la Chinea, puesto que suponía el momento álgido de demostración de poder de la corona española en la ciudad y por tanto su valor simbólico era trascendental para mantener el equilibrio de poderes en la ciudad. MuniAín, «Arquitecturas efímeras», 2005, p. 64.

30. Moore, «Building set pieces», 1998/1999, p. 238. 
da solemne en Nápoles el 3 de julio ante el júbilo de sus súbditos, cuyo último contacto directo con sus monarcas fue en el lejano 1702 con la fugaz visita de Felipe V para su aclamación. En agosto se consuma la destitución del conde de Santiesteban, que supone la victoria de la facción de la nobleza napolitana en la que el cardenal Acquaviva tenía obvios intereses y éste comienza a preparar la fiesta para celebrar la unión de los jóvenes monarcas napolitanos en Roma. En términos políticos, Troyano se encuentra en un momento de grandes éxitos, no sólo por haber asegurado la investidura, que le concedería el favor de la reina de España así como la gratitud de los reyes de Nápoles y las Dos Sicilias, sino porque además se coloca al lado de la nueva facción que gobernará la corte de Nápoles en los próximos años ${ }^{31}$. En este contexto, en el punto álgido de su poder e influencia, es donde debemos situar la fiesta que organiza en Roma.

La última celebración de características similares que vivió el palacio de España en Roma fue la del doble matrimonio de las dos coronas ibéricas en 1728 bajo el embajador Bentivoglio y todavía se conservaba en la memoria de la ciudad por su fastuosidad ${ }^{32}$. Ante un precedente así, sin duda, Troyano Acquaviva se vio impelido a emular y obviamente superar a su antecesor, celebrando la unión de los jóvenes reyes de Nápoles y las Dos Sicilias, en cuyo ascenso y consolidación en el trono partenopeo tanto había invertido.

Los festejos duraron dos días y comenzaron con el encendido el sábado 6 de septiembre de la máquina de fuegos de artificio (Fig. 1, Museo di Roma, 2129) diseñada por Ferdinando Fuga (1699-1781) ${ }^{33}$. La máquina se pensó en primer lugar para situarla en la plaza de Mignanelli y se comenzó a montar allí. La elección del lugar estaba obviamente vinculada a la mejor perspectiva desde los salones del palacio de España (Fig. 2, detalle del plano de Nolli, en el cuadrado amarillo). La plaza Mignanelli es, sin embargo, un espacio que podría resultar angosto, dado que su entrada natural es más estrecha que el fondo y podría causar problemas por el número de visitantes que se esperaba. A ello hay que añadir que sólo poseía un único acceso simple, lo que no

31. VÁZQUEZ GESTAL, «The system of this court», 2009, desarrolla detalladamente la estructura previa de la corte en los primeros años de Carlos de Borbón. La sustitución del conde de Santiesteban por el marqués de Montealegre, de origen napolitano, supone un giro de timón en la política que Isabel de Farnesio había impuesto a través de su hijo y su antiguo Mayordomo.

32. Sobre la fiesta barroca existen una abundantísima bibliografía en la que no me voy a detener, véase para ello Martínez Hernández, Santiago: «Cultura festiva y poder en la monarquía hispánica y su mundo: convergencias historiográficas y perspectivas de análisis», Studia Historica, 31 (2009), pp. 127152. Para el caso romano conviene citar a VISCEGLIA, Maria Antonietta: La città rituale: Roma e le sue cerimonie in età moderna, Roma, 2001, que analiza el ceremonial relativo a las celebraciones religiosas y políticas como síntoma del poder papal. En concreto sobre la fiesta en el Settecento sigue siendo de referencia la obra de FAGIOLO, Marcello (coord..): Il Settecento e L'Ottocento, Corpus delle feste a Roma 2, Roma, 1997, volumen que complementa el de Fagiolo Dell'Arco, Maurizio: La Festa Barocca, Corpus delle feste a Roma, Roma, 1997. Sobre la fiesta española de este período véase: ToRRIONE, Margarita (coord.): España festejante: el Siglo XVIII, Málaga, 2000.

33. KIEVEN, Elisabeth: Ferdinando Fuga e l'architettura romana del Settecento: $i$ disegni di architettura dalle collezioni del Gabinetto nazionale per la Grafica, Roma, 1988, cat. 70. 


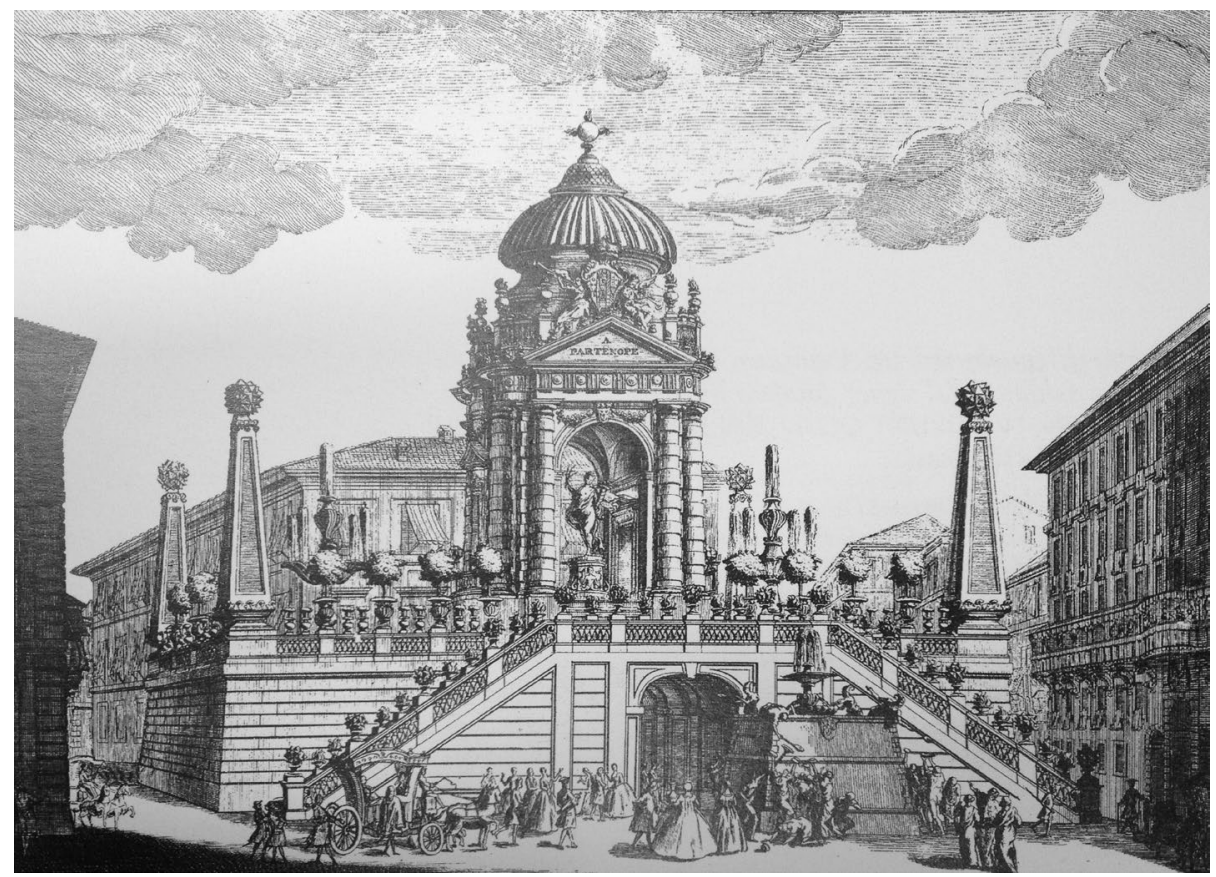

Fig. 1: Máquina de artificio de Ferdinando Fuga para el matrimonio de Carlos de Borbón y María Amalia de Sajonia en Roma, 1738.

es una tema menor en una estructura de esa envergadura que pretendía arder al final de los festejos. El traslado a la plaza de España, delante de la fachada del palacio de Propaganda Fide, se podría explicar no sólo porque permitía una mayor concurrencia al espectáculo, sino porque también contaba con tres accesos laterales por via Frattina, via dei Due Macelli y via de Propaganda (Fig. 2, detalle del plano de Nolli, en el cuadrado rojo $)^{34}$.

La estructura era bastante sobria (fig. 1): sobre una plataforma rectangular rematada en cada esquina con pináculos acabados en poliedros se colocaba un templete de plan central con una cúpula. En el interior se cobijaba una figura dorada de una ninfa, que sostenía una cornucopia rebosante en la mano izquierda, y en la derecha dos espigas de trigo. Se levantaba sobre una basa decorada con una sirena de doble cola, imagen de la ciudad de Nápoles. El templo presenta una inscripción en el frontón, «A Parténope», que no deja lugar a dudas del significado de la figura alegórica, que alude a la prospe-

34. VALESIO, vol. VI, p. 163. Las medidas de la máquina están recogidas en la «Relazione» (AHN, Exteriores, SS 477, fol. 24) 125 palmos romanos de altura por 134 palmos de ancho, ocupando la casi totalidad del frente del palacio de Propaganda Fide. El palmo romano se corresponde aproximadamente con $22 \mathrm{~cm}$. 


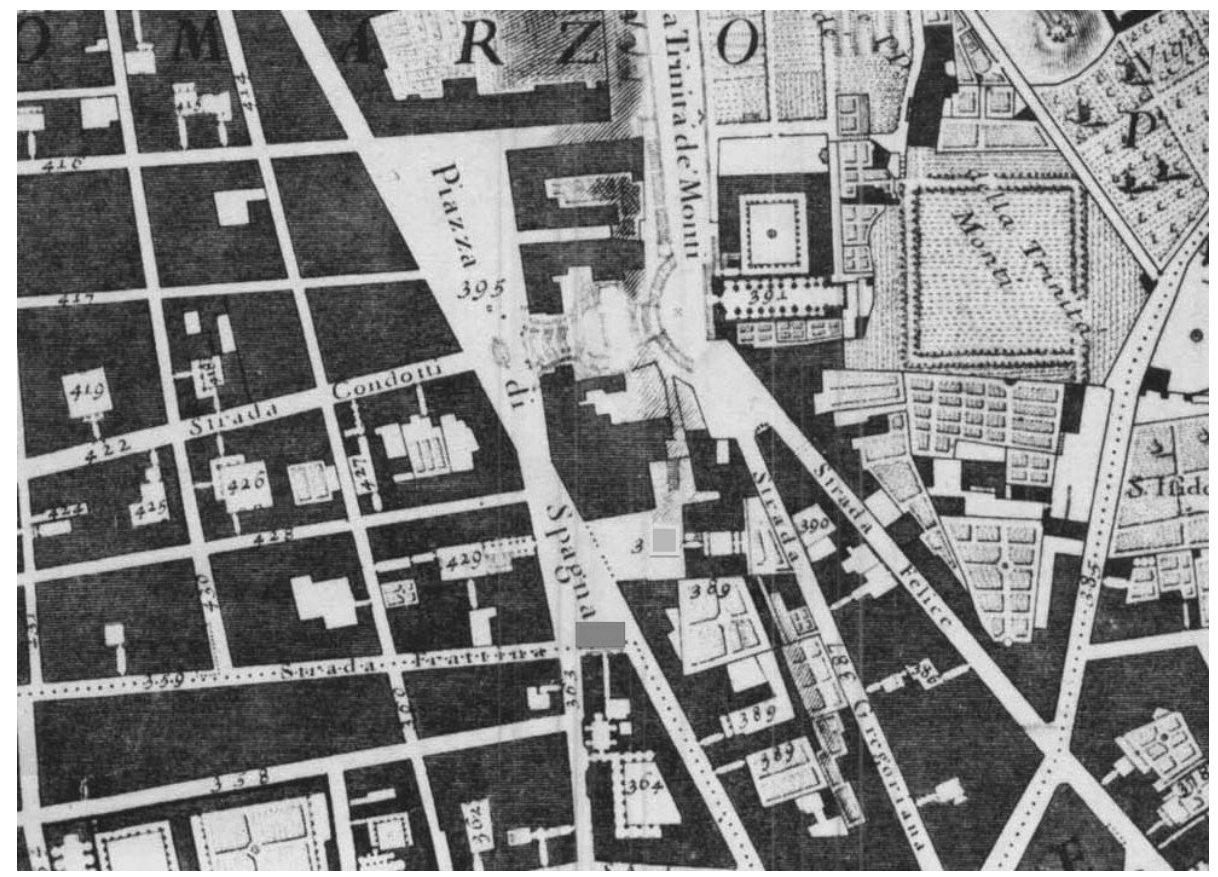

Fig. 2: Detalle de la Plaza de España, Mapa de Roma, Nolli, 1748.

ridad y la fertilidad, aspectos comunes en la iconografía nupcial desde la Antigüedad. A la máquina se accede a través de una escalera de doble tiro cuyos balaustres, al igual que los de la estructura superior, están decorados con vasos, urnas llameantes y globos poliédricos. El conjunto se completa con pequeños arbustos de naranjos.

A tenor de las descripciones que conservamos de Valesio o del Diario Ordinario (Chracas), lo que causó mayor admiración fue el sistema de iluminación de la arquitectura, puesto que la luz venía del interior de las esferas y los vasos, «il tutto è trasparente ed illuminata dal di dentro» ${ }^{35}$. Tanto es así que Nipho en su redacción de lo acontecido habla de «la nueva invención del fuego artificial», que permitió mantener la máquina encendida los dos días. Desgraciadamente ninguna de las descripciones de la época detallan el novedoso sistema de luz «artificial».

Por último, el conjunto se completaba con una pequeña estructura con forma de bastión cuadrangular con cuatro leones de los manaban vino tinto y blanco. La fuente funcionó los dos días de la celebración y era atendida por «cuatro ridículos jorobados $»^{36}$.

35. Chracas, Diario Ordinario di Roma, 1738, n. 3295, pp. 2-7 y VALESIO, vol. VI, p. 169-170. 36. AHN, Exteriores, SS 477, fol. 24 


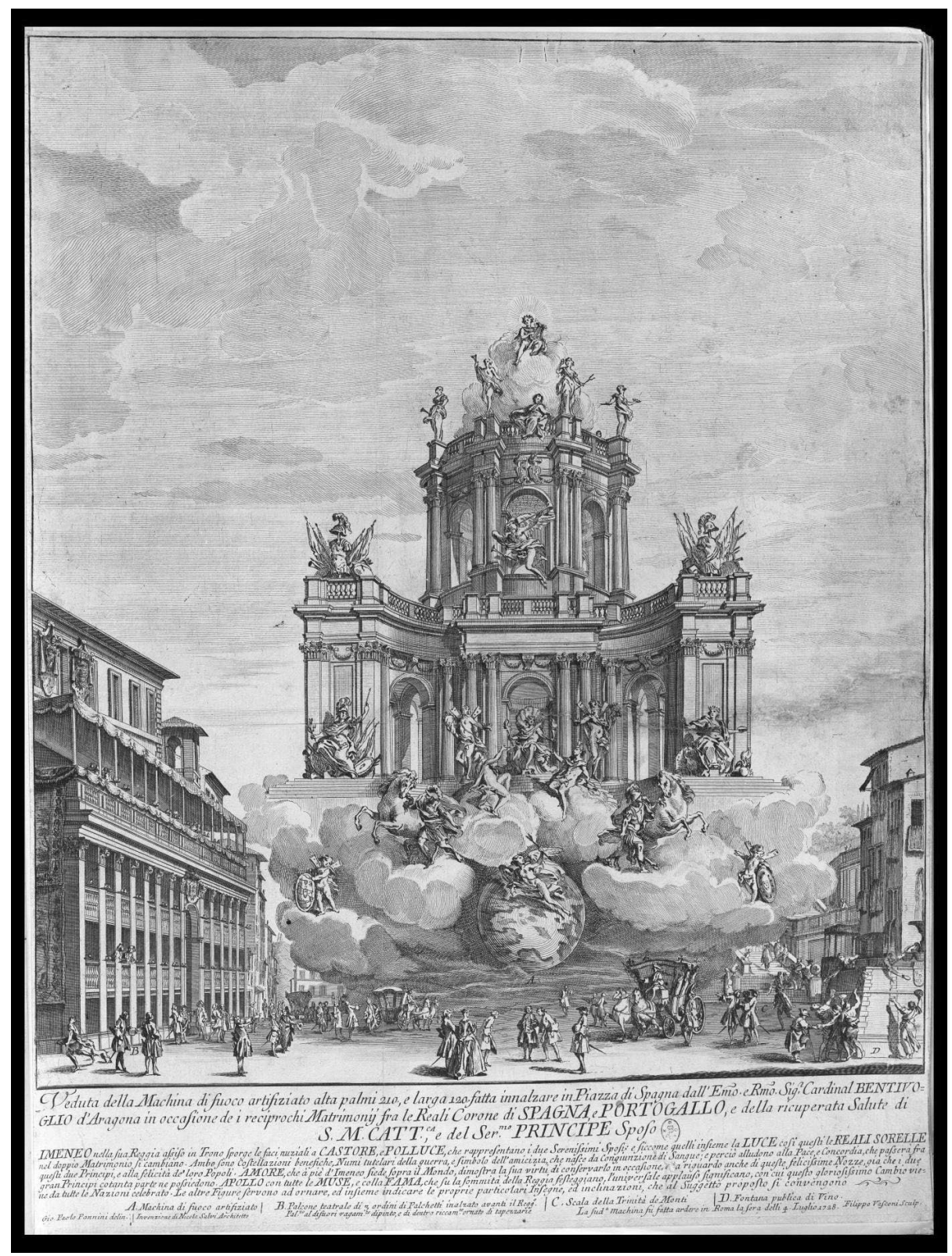

Fig. 3: Máquina de artificio de Nicola Salvi para los dobles esponsales luso-españoles en Roma, 1728. 
El diseño de la máquina era obra de Ferdinando Fuga, arquitecto protegido por Troyano Acquaviva que con este encargo inauguraba una exitosa serie de trabajos para los monarcas de Nápoles y las Dos Sicilias. Su obra se debe entender en comparación con la que Nicola Salvi (1697-1751) ideó para la fiesta de los dobles esponsales lusoespañoles en 1728. En esos años Fuga ya llevaba diez años en Roma, pero en 1726 se trasladó a Nápoles para trabajar en el palacio Cellamare, encargo que había conseguido a través del cardenal Giudice. No sabemos si estuvo en Roma en el momento de la celebración, el 4 de julio, y si llegó a ver la máquina de Salvi, que sin duda era uno de sus grandes competidores, pero la repercusión de la fiesta organizada por el cardenal Belluga fue lo suficientemente importante como para que conociese el grabado de Giovanni Paolo Panini (Fig. 3; Biblioteca Casanatense, Roma, RM0313).

La máquina de Salvi se diseñó para colocarse sobre la fuente de la Barcaccia, delante de las escalinatas de la plaza de España. La estructura arquitectónica tenía una base de 120 palmos romanos, esto es más estrecha que la de Fuga y mucho más alta, pues alcanza los 175 palmos. Ese desequilibrio entre base y altura se ve acentuado por el diseño. Salvi opta por una ensoñación arquitectónica que surge de una base de nubes con un enorme globo terráqueo gobernado por Eros. Sobre las nubes se asienta una magnífica arquitectura central con dos alas que sirve de suntuosa hornacina para el dios Himeneo en el acto de entregar las llamas nupciales a los hermanos Cástor y Pólux. El conjunto se cierra con joven Febo que coronado de rayos toca la lira sentado sobre otro grupo de nubes que hace las veces de linterna de la estructura.

Es obvio que los diez años que median entre ambas celebraciones han supuesto un cambio sustancial en la concepción de estas fabulosas máquinas. Fuga nos ofrece una arquitectura real y plausible, esto es, se aleja de las creaciones más acordes con el mundo teatral y operístico de espacios oníricos sostenidos por nubes y carentes de lógica constructiva en la mayoría de los casos. El florentino propone una estructura sobria y limpia en la que los elementos alegóricos tienen su lugar en un espacio construido real y donde la luz tiene un importante papel. El éxito fue inmediato y probablemente eso explique que se le vuelva a encargar la máquina de artificio de la fiesta del matrimonio de los reyes de Nápoles, que se celebró en la ciudad partenopea en el verano de 1739.

Además del indudable espectáculo visual, la máquina ofrecía así mismo un espectáculo sonoro. En las escaleras se situaban los músicos que tocaban para disfrute de los visitantes y que eran un elemento fundamental en estas celebraciones. Las fuentes hablan de «istromenti da fiato», que es un término un tanto ambiguo puesto que puede referirse tanto a vientos en madera o metal ${ }^{37}$. Por un lado, los vientos de metal serían instrumentos asociados tradicionalmente a los triunfos $\mathrm{y}$, por tanto, perfectamente adecuados al contexto de la corona de las Dos Sicilias que acababa de volver a manos españolas. Por otro, los vientos de madera tienen un indudable gusto pastoral,

37. «facendo dilettevole trattenimento alli spetatori vari concerti d'istromenti da fiato posti nei ripiani delle due grandi scale che formavano base alla macchina sopradescritta» (CHRACAS, 1738, n. 3295, pp. 2-7). 
que vendrían a subrayar el modelo arcade que se encuentra detrás de estas fiestas, que incluyen música, arte, baile, aspecto que ya ha sido señalado por otros especialistas ${ }^{38}$. No en vano Fuga era un miembro de la Academia de la Arcadia en donde ingresó acompañado por su esposa, Angela Ponetti, bajo el nombre de Dédalo Ippodromaico a finales de los años veinte ${ }^{39}$.

El palacio y las casas circundantes estaban también ricamente adornadas en sus fachadas e iluminadas suntuosamente. La importancia de la iluminación como medio de señalar una ocasión especial es algo recurrente en las fuentes, llegando incluso a existir todo un ceremonial que marcaba el número de antorchas y el tipo de iluminación que cada ocasión requería ${ }^{40}$.

El domingo 7 de septiembre se inició con un recibimiento en el Palacio de España, siguiendo la costumbre habitual en la que los prelados, príncipes y demás personalidades pasaban a dar la enhorabuena o felicitar al embajador y después todos ellos eran invitados a un «refresco de bebida, chocolates y dulces». El día continuó con una celebración religiosa en la Iglesia del Espíritu Santo de los Napolitanos, en donde se cantó un Te Deum como señal de agradecimiento del que no conocemos el compositor ${ }^{41}$. El cortejo fue especialmente numeroso puesto que Troyano llevó catorce carrozas, además de la suya, dejando patente la importancia de dicha celebración. En la iglesia le esperaba el capellán Mayor del rey de Nápoles y las Dos Sicilias, Monseñor Celestino Galiani, que oficiaría la misa. Troyano aparecía de gala vestido con la Capa Magna y junto con los cardenales Giudice, Alessandro Albano y Belluga, que acompañaron el servicio religioso ${ }^{42}$.

Una vez terminado el servicio religioso, la comitiva regresó al palacio para continuar con el «festejo de fuegos», al que estaba invitado todo el Sacro Colegio, los ministros de los soberanos, así como todo príncipe, prelado, caballero y vasallo. Una parte fundamental de estas fiestas era la respuesta por parte del resto de la sociedad,

38. Este aspecto lo trata Muniaín, «Arquitecturas efímeras», 2005, p. 64.

39. No en vano los jóvenes reyes de Nápoles entrarían a formar parte de la Arcadia bajo los nombres de Eraclide Samio y Olimpia Hesperia en el agosto de 1748. Adunanza tenuta nel Bosco Parrasio per l'acclamazione seguita in Arcadia delle Sacre Reali Maestà di Carlo di Borbone e Maria Amalia di Sassonia Re, e Regina delle Due Sicilie il giorno delle Calende di Agosto dell'Anno MDCCXLVIII. Alla Presenza dell'Eminentissimo, e Reverendissimo Sig. Cardinale Domenico Orsini Protettore de'suddetti due Regni fra gli Arcadi Accl. Rodaspe Agoretico.

40. «(...) se pusieron luminarias en las noches de los día 6 y 7 del corriente por todo el ventanaje de las tres andanas del Real palacio y por todas las casas de la Plaza y circunvecinas, a cuyo efecto mandó su Eminencia repartirlas a proporción de las ventanas, que cada casa tiene, y lo mismo ejecutaron diferentes iglesias nacionales, palacios de varios cardenales, de todos los príncipes vasallos, y feudatarios, de las Coronas de España y Nápoles, y así mismo de todos los ministros de príncipes extranjeros y de otros muchos afectos a entrambas coronas». AHN, Exteriores, SS 477, fol. 24.

41. El cardenal Acquaviva había tomado posesión como protector de esa iglesia el pasado día 3 de septiembre, después de la renuncia del cardenal Ferrao. VALESIO, vol. VI, p. 169.

42. Faltaba el cardenal Ottoboni, que en esa mañana se encontraba recibiendo del Pontífice el palio del obispado de Ostia. AHN, Exteriores SS, 477, fol. 24. 
puesto que el nivel de influencia y de poder de un embajador se medía en tanto en cuanto consiguiese atraer a un mayor número de personalidades. Además de todos los invitados varones, Nipho hace una especial mención a la concurrencia de numerosas damas, que eran atendidas por la duquesa Strozzi, es decir la Isabella Acquaviva, la hermana de Troyano, casada con Filippo Strozzi.

El día continuó con una serie de refrescos para los invitados y sólo a la noche se procedería a la quema de la máquina de artificio. Nipho señala que se esperó a la llegada del rey de Inglaterra y sus dos hijos, los Stuart, cuya relación con Troyano era muy estrecha e incluso solían disfrutar de los palcos del teatro reservados por el embajador. La deferencia especial que Troyano tenía con los pretendientes ingleses se pone de manifiesto cuando comienza con ellos para despedir a los presentes una vez terminada la quema. Nipho da cuenta de todos los invitados en una relación que adjunta al final de la descripción de la fiesta y que nos permite ver la envergadura de la misma.

Si esta fiesta fue un punto de inflexión en la carrera diplomática de Troyano Acquaviva quizás pueda ser una afirmación discutible o matizable para muchos, pero lo cierto es que políticamente, Troyano fue capaz de afianzar su posición que tan sólo un año antes era endeble y convertirse en el embajador más poderoso de Roma ante su grandes oponentes, el embajador cesáreo y el francés. A través de la Hacanea y la fiesta del matrimonio de los reyes de Nápoles hace patente la pujante presencia española, tomando el espacio público y connotándolo con los símbolos de las dos coronas que representa. En este sentido la celebración del Te Deum en la iglesia del Espíritu Santo de los Napolitanos es un paso más en esa conquista de los espacios de la ciudad. Las iglesias nacionales en Roma eran lugares estratégicos que permitían a los representantes de las diferentes naciones tener una presencia activa en una la trama urbana en la que era difícil hacerse un hueco ${ }^{43}$. El caso español vuelve a ser bastante excepcional puesto que no sólo contaba con la Iglesia de San Giacomo degli Spagnoli y Santa María del Monserrato, sino que ahora añadía a las iglesias de los napolitanos y sicilianos $^{44}$.

43. Las iglesias nacionales son un asunto que ha despertado justamente el interés de especialistas de diferentes áreas y cuyas publicaciones nos están permitiendo disfrutar de un conocimiento mucho más profundo de la interacción de las diferentes naciones y su huella en el tejido urbano romano. En el campo de la historia del arte cabe destacar el trabajo que se está realizando el grupo de investigación Minerva liderado por Susanne Kubersky-Piredda (http://www.biblhertz.it/it/attivita-di-ricerca/progetti-di-ricercadellistituto/gruppo-di-ricerca-minerva/) y en el de la musicología, el proyecto sobre la música en las iglesias nacionales, dirigido por Emilie Corswarem (http://web.philo.ulg.ac.be/transitions/le-modele-musical-des-eglises-nationales-a-rome-a-lepoque-baroque/): Michela Berti, Michela: «Tra 'Regolamenti' e 'musiche straordinarie': la presenza di musicisti stranieri a San Luigi dei Francesi e nelle altre Chiese Nazionali di Roma», en Goulet, Anne-Madeleine y Zur NiEden, Gesa (coord.) Europäische Musiker in Venedig, Rom, und Neapel. 1650-1750, Analecta Musicologica, 52 (2015), pp. 397-424; CorSWAREM, Emilie: «Una nazione ricostruita: musica e feste delle confraternite tedesche e fiamminghe a Roma», en Goulet, Anne-Madeleine y Zur Nieden, Gesa (coord.) Europäische Musiker in Venedig, Rom, und Neapel. 1650-1750, Analecta Musicologica, 52 (2015), pp. 425-441.

44. Anselmi, Alessandra: Le chiese spagnole nella Roma del Seicento del Settecento, Roma, 2012 y en concreto sobre la iglesia napolitana: VENTURA, Piero: «Identidad y patronazgo de la nación napolitana en Roma. La Archicofradía del Espíritu Santo entre los siglos XVI y XVIII», GARCía García, Bernando y 
En cuanto a acumulación real de espacios de poder, Troyano Acquaviva se encontraba en una posición de enorme ventaja frente a la presencia palpable de sus principales rivales, esto es, el embajador de Francia y el Cesáreo. No sólo había hecho patente que la herencia de los Farnese era ahora también española, sino que también sus maniobras diplomáticas habían ayudado a asegurar el Reino de Nápoles y las Dos Sicilias para Don Carlos de Borbón y con ello las iglesias nacionales pasaban a la órbita española.

Acquaviva encarna la imagen del perfecto cortesano que combina su amplia experiencia en lides políticas con un profundo conocimiento de los ceremoniales romanos. $\mathrm{Su}$ recorrido vital, siendo hijo de un exiliado como Giovan Girolamo Acquaviva y madurado en el complicado entorno que su tío Francesco vivió en Roma, es una elemento que no podemos desdeñar a la hora de comprender sus aspiraciones políticas, sus ambiciosas campañas, su cuidado mecenazgo y sobre todo su refinado y exquisito uso de los modos de la diplomacia y su parafernalia. Su red familiar es un aspecto que hemos visto presente en estos primeros años de embajador, por un lado su hermano Domenico, Duque de Atri, que era Grande de España y capitán de la Real Guardia de Corps y mantenía una estrecha relación con la reina Isabel de Farnesio con la que, como ya señalamos, compartía una continua correspondencia que la mantenía informada de todo lo que sucedía en la corte napolitana. Por otro lado, Troyano contaba además con la discreta, pero indispensable ayuda de su hermana Isabella, la duquesa Strozzi, que era una pieza esencial en las numerosas veladas festivas que se organizaban en el palacio.

La embajada de Troyano obtuvo numerosos éxitos, mas no estuvo tampoco exenta de sombras, sin embargo su refinado olfato le permitió esquivar con elegancia los estoques de sus enemigos ${ }^{45}$ y salir reforzado en su papel de gran príncipe de la Iglesia al servicio de las dos coronas españolas que gracias a él habían recuperado en gran parte su antiguo prestigio en la ciudad pontificia.

Recio Morales, Oscar (coord.), Las corporaciones de nación en las Monarquía Hispánica (1580-1750),

Madrid, 2014, pp. 265-277.

45. Véase Muniaín, n. 79 y 80. 